\title{
Endocardite infecciosa em câmaras direitas: discrepância entre evolução clínica e ecocardiográfica: relato de caso
}

\author{
Right-side infective endocarditis: discrepancy between clinical and \\ echocardiographic evolution: case report
}

\author{
Bruno Ramos Nascimento ${ }^{1}$, Thaíssa Oliveira de Almeida A. Coelho ${ }^{3}$, \\ Lucas Rocha da Costa Filho ${ }^{1}$, Marcelo Martins Pinto Filho ${ }^{1}$, Vitor Emanuel Serafim Cota ${ }^{1}$, \\ Renata de Carvalho Bicalho ${ }^{1}$, Antonio Luiz Pinho Ribeiro ${ }^{1,2}$ \\ e Maria do Carmo Pereira Nunes ${ }^{1,2}$
}

\begin{abstract}
RESUMO
A endocardite infecciosa é uma patologia relativamente rara na prática clínica, e, apesar dos avanços em seu diagnóstico e tratamento, sua morbimortalidade ainda é significativa. Muitas vezes é difícil a identificação de suas complicações e a conduta frente a elas, ocorrendo com frequiência a dissociação entre a evolução clínica e os achados de exames complementares - principalmente ecocardiográficos. A decisão clínica torna-se ainda mais difícil frente às manifestações atípicas da doença, como a endocardite de câmaras direitas. Este é o relato de um caso raro de endocardite de câmaras direitas em uma paciente renal crônica, cuja piora dos achados ecocardiográficos se opunha à evolução clínica favorável. Esta situação pode suscitar dificuldade quanto aos critérios para indicação cirúrgica e a segurança do tratamento conservador.
\end{abstract}

Palavras-chaves: Endocardite. Câmaras direitas. Manejo clínico. Tratamento.

\begin{abstract}
Infective endocarditis is a relatively rare disease in clinical practice, with significant morbidity and mortality despite the improvements on its diagnosis and treatment. It is often difficult to identify its complications and define strategies for them. Dissociation between the clinical evolution and the findings from complementary tests (especially echocardiographic tests) is common. Clinical decisions become even more difficult when there are atypical manifestations of the disease, such as right-side endocarditis. This report is about a rare case of right-side endocarditis in a patient with chronic renal disease, in which there was a contradiction between worsening of the echocardiographic findings and clinical improvement. This situation may lead to difficulties regarding the criteria for indicating surgery and the safety of conservative clinical treatment.
\end{abstract}

Key-words: Endocarditis. Right-side chambers. Clinical management. Treatment.

Endocardite infecciosa (EI) é uma doença grave, mantendo alta mortalidade a despeito dos avanços em seu diagnóstico e tratamento. 0 perfil clínico dos pacientes com EI está mudando e novos fatores predisponentes estão sendo identificados. Pacientes portadores de insuficiência renal crônica em programa de hemodiálise constituem um novo grupo de risco EI.

O papel do ecocardiograma no diagnóstico da EI é claro, mas o seu valor no acompanhamento e prognóstico não está definido. 0 relato a seguir descreve um caso de EI em câmaras direitas em uma paciente renal crônica, em hemodiálise por meio de catéter de duplo lúmen.

1. Serviço de Cardiologia e Cirurgia Cardiovascular, Hospital das Clínicas, Universidade Federal de Minas Gerais, Belo Horizonte, MG. 2. Departamento de Clínica Médica, Faculdade de Medicina, Universidade Federal de Minas Gerais, Belo Horizonte, MG. 3. Serviço de Clínica Médica, Hospital das Clínicas, Universidade Federal de Minas Gerais, Belo Horizonte, MG.

Endereço para correspondência: Dr. Bruno Ramos Nascimento. Rua Tenente Anastácio de Moura 740/602, 30240-390 Belo Horizonte, MG.

Tel: 5531 3227-1123; Fax: 5531 3409-9437

e-mail: ramosnas@uol.com.br

Recebido para publicação em 27/02/2009

Aceito em 21/08/2009

\section{RELATO DO CASO}

Paciente do sexo feminino, raça branca, 47 anos, portadora de doença renal crônica secundária a nefrolitíase obstrutiva, em hemodiálise há 5 meses, via cateter de duplo lúmen. Relatava alguns episódios febris nesse período, sendo feitas trocas de cateter, mas não definido foco ou agente infeccioso e não utilizada antibioticoterapia.

Internada no Hospital das Clínicas da Universidade Federal de Minas Gerais com dez dias de evolução de dor migratória em membros inferiores e articulação têmporo-mandibular, vômitos e febre alta $\left(40^{\circ} \mathrm{C}\right)$. Ao exame, estado geral comprometido. Hidratada e hipocorada. PA: 125/70mmHg, FC: 108bpm. Ritmo cardíaco regular, sopro sistólico II/VI de Levine, em foco pulmonar, com aumento da intensidade à inspiração. Baço palpável a $4 \mathrm{~cm}$ do rebordo costal esquerdo e fígado a $2 \mathrm{~cm}$ do rebordo costal direito, indolores. A paciente negava passado de cardiopatias, etilismo, tabagismo ou uso de drogas ilícitas. Não havia história de afecções ginecológicas ou doenças sexualmente transmissíveis. 
Exames laboratoriais à admissão mostravam: hemoglobina de $7,8 \mathrm{~g} / \mathrm{dl}$, hipocromia e microcitose; leucocitose $\left(14.150 \mathrm{cel} / \mathrm{mm}^{3}\right.$ com $20 \%$ de bastonetes) e PCR (proteína C reativa) de 480mg/L. As três amostras de hemoculturas - colhidas em sítios diferentes a intervalos de 30 minutos - foram negativas. Eletrocardiograma e RX tórax sem alterações. Diante deste quadro, várias hipóteses diagnósticas iniciais foram formuladas, como leishmaniose visceral (calazar), esquistossomose hepatoesplênica (por se tratar de paciente de área endêmica), artrite reativa e endocardite infecciosa, sendo iniciado ceftriaxone empiricamente.

Outros exames complementares foram realizados, como mielograma, o qual foi negativo para leishmaniose, e ultrassom abdominal, que mostrou discreta hepatoesplenomegalia, com sinais de hepatopatia periportal sugestiva de esquistossomose. Morfologia renal alterada, com atenuação da diferenciação córtico-medular.

Ecocardiograma transesofágico (ECO TE) evidenciou imagem de cateter em átrio direito e estrutura filiforme, em espiral, próxima ao apêndice atrial direito (Figura 1A). Além disso, observou-se imagem sugestiva de vegetação em valva pulmonar, face ventricular, móvel, medindo 17x8mm e outra no átrio direito, à entrada da veia cava superior, medindo $5 \mathrm{~mm}$ (Figura 1B).
Novas hemoculturas isolaram Staphylococus aureus meticilino-resistente (MRSA) em três amostras. Foi retirado o cateter de diálise e trocados antimicrobianos para vancomicina e gentamicina. A paciente evoluiu com rápida piora do estado geral, vômitos incoercíveis acompanhados de confusão mental e rebaixamento do nível de consciência. Foi avaliada pela neurologia, com hipótese diagnóstica de encefalopatia metabólica. Tomografia de crânio sem alterações. Houve melhora gradual do quadro após a troca dos antimicrobianos. Devido à persistência de anemia ferropriva importante, foram necessárias hemotransfusões e posterior associação de sulfato ferroso e eritropoietina.

Observou-se melhora clínica geral, com desaparecimento da febre e redução da hepatoesplenomegalia. Houve queda da PCR, porém mantendo-se leucocitose de 20.000/ml. Novas hemoculturas foram negativas. À ausculta, houve surgimento de atrito pericárdico, mas o quadro hemodinâmico se manteve estável, não se evidenciando piora. Foi então solicitado novo ECO TE, que mostrou pequeno derrame pericárdico e nova vegetação, de 30mm, aderida ao átrio direito, próximo ao apêndice atrial, prolapsante pela valva tricúspide. Vegetações prévias de valva pulmonar e átrio direito inalteradas (Figuras 1C e 1D).

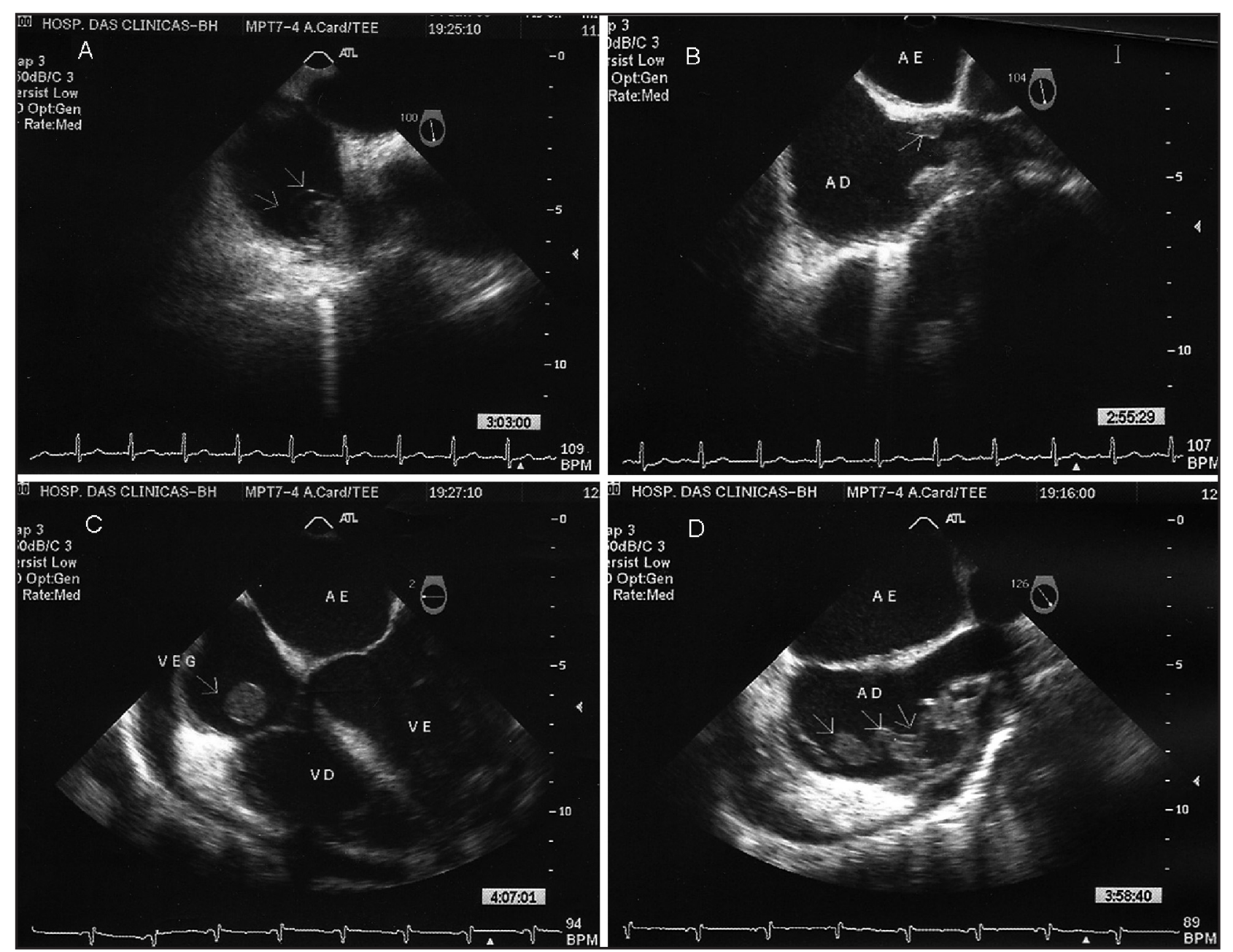

FIGURA 1

1A: Catéter em átrio direito e imagem de estrutura filiforme, em espiral, próxima ao apêndice atrial direito. 1B: imagem sugestiva de vegetação móvel em valva pulmonar, face ventricular. 1C: Eco de controle (3 semanas): vegetação prévia em valva pulmonar inalterada. 1D: Eco de controle (3 semanas): pequeno derrame pericárdico e nova vegetação, de 30 mm, aderida ao átrio direito, próximo ao apêndice atrial, prolapsante pela valva tricúspide. 
Foi considerado o diagnóstico de endocardite refratária ao tratamento clínico e levantada possibilidade de tratamento cirúrgico. Contudo, o surgimento de nova imagem de vegetação ao ECO TE se contrapunha à estabilidade clínica e ao bom estado geral da paciente. Foi descartada uma possível intervenção cirúrgica naquele momento e mantido tratamento clínico. A paciente recebeu alta em bom estado geral, retornando após 1 mês, assintomática e sem alterações no exame cardiológico. Houve desaparecimento da hepatoesplenomegalia e negativação da PCR. Além disso, apresentava-se sem leucocitose ou anemia. Foi realizado novo ECO TE (4 meses após alta), que evidenciou ausência de vegetações intracardíacas, função biventricular preservada e sem disfunções valvares (Figuras 2A e 2B).

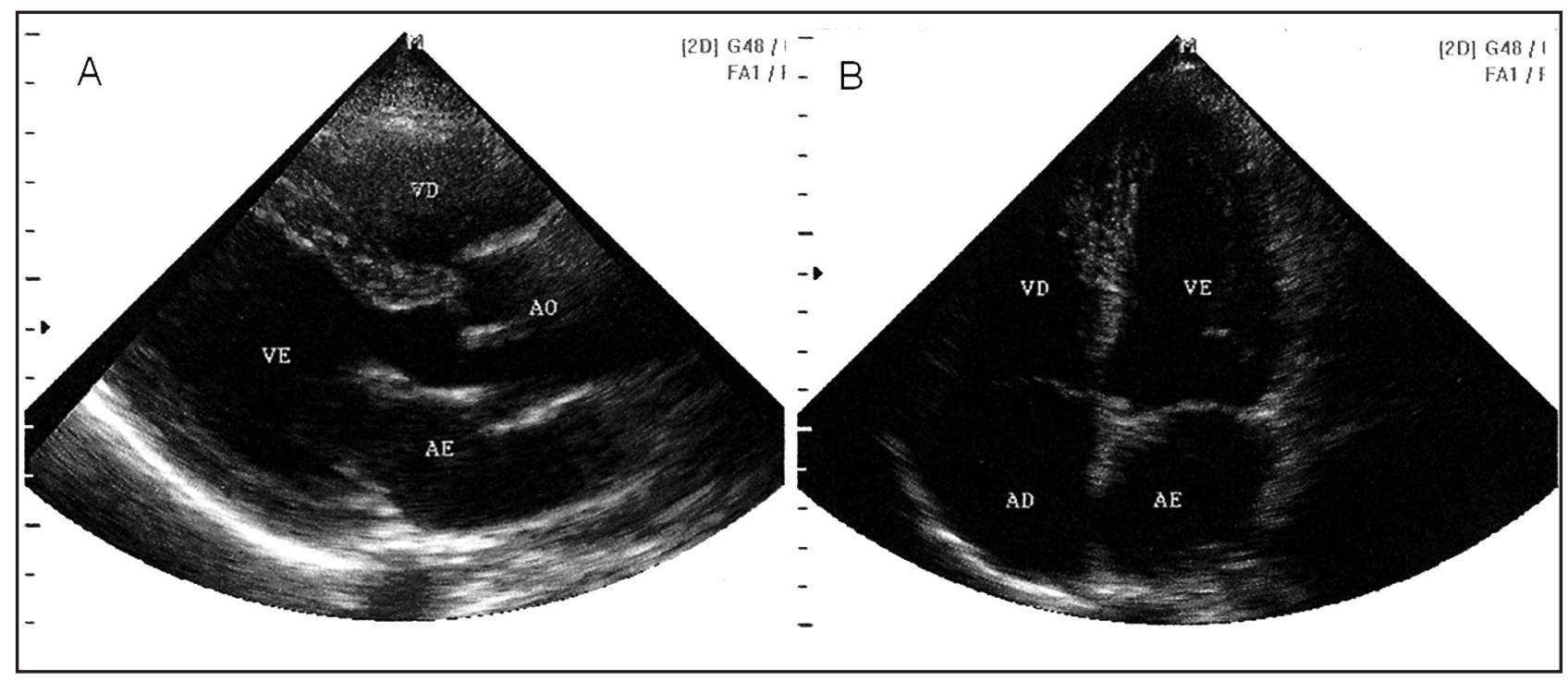

FIGURA 2A E 2B

Ecocardiograma de controle ( 4 meses após a alta hospitalar), mostrando resolução das vegetações observadas nos exames anteriores.

\section{DISCUSSÃO}

Trata-se de um caso de apresentação rara da endocardite infecciosa (EI), - em termos da dissociação clínicoecocardiográfica - acometendo valva pulmonar e câmaras direitas (correspondem a 1 a $1.5 \%$ dos casos de endocardite infecciosa $)^{2}$. Tal acometimento é mais comumente observado em crianças portadoras de cardiopatias congênitas. Em adultos, tal condição está associada à utilização de drogas ilícitas endovenosas e etilismo, além de cateteres venosos centrais, como neste caso. Em geral, a endocardite direita apresenta melhor evolução e leva menos comumente à disfunção cardíaca grave ${ }^{2}$.

No caso apresentado, a paciente era renal crônica em tratamento dialítico, situação em que as complicações infecciosas em acessos vasculares são uma das maiores causas de morbimortalidade ( $10 \%$ dos óbitos), perdendo apenas para a doença arterial coronariana ${ }^{4}$. Nesta população, observa-se bacteremia em um em cada 100 pacientes/mês, atrás apenas dos neutropênicos pós-quimioterapia e usuários de drogas endovenosas ${ }^{4}$. Além disso, a degeneração e calcificação precoces das valvas cardíacas são fatores predisponentes à colonização $0^{6}$, resultando em taxas de EI entre 2 a 6\%. 0 principal agente infeccioso neste grupo é o Staphylococcus aureus, frequentemente meticilino-resistente.

0 ecocardiograma tem papel fundamental no diagnóstico e na identificação de complicações da EI. 0 consenso americano de EI (American College of Cardiology/American Heart Association/ American Society of Echocardiography) propõe a realização de novo ECO durante o tratamento no caso de microorganismos virulentos (inclusive o Staphylococcus aureus), comprometimento hemodinâmico, envolvimento de valva aórtica, febre ou bacteremia persistente (intratabilidade clínica), alterações ou deterioração clínica a despeito do tratamento (indicações Classe I) ${ }^{1}$. Além disso, preconiza-se o ECO ao final do tratamento para avaliação de lesões valvares residuais ${ }^{3}$. Um estudo, reavaliando casos de endocardite infecciosa direita e esquerda com novo ECO, realizado entre três semanas e três meses após o final do tratamento, mostrou que 30\% das vegetações desaparecem, $18 \%$ reduzem, $41 \%$ permanecem inalteradas e 11\% aumentam suas dimensões 7 . Já se demonstrou o impacto prognóstico negativo do aumento das vegetações no seguimento ecocardiográfico ${ }^{5}$.

No caso em questão, o novo ECO era uma indicação Classe I. No entanto, a piora ecocardiográfica contrastava com a melhora clínica da paciente. Soma-se a este dado o fato de as indicações cirúrgicas na endocardite direita serem ainda mais restritas do que na endocardite de câmaras esquerdas, restringindo-se quase unicamente à persistência da febre e/ou bacteremia ou endocardite fúngica. $\mathrm{O}$ tamanho da vegetação e mesmo a ocorrência de infiltrados pulmonares persistentes não indicam a abordagem invasiva ${ }^{3}$. Desta forma, este caso ilustra a evolução clínica favorável a despeito do ecocardiograma detectar crescimento de vegetação em um caso de endocardite em câmaras direitas, observando-se dissociação clínico - ecocardiográfica. Deve-se considerar, no entanto, outras causas para tal dissociação, como as limitações e o caráter examinador-dependente da ecocardiografia, além de outras possibilidades, como a presença de trombo nas cavidades mimetizando uma vegetação. 


\section{REFERÊNCIAS}

1. Baddour LM, Wilson WR, Bayer AS, Fowler Jr VG, Bolger AF, Levison ME, Ferrieri P, Gerber MA, Tani LY, Gewitz MH, Tong DC, Steckelberg JM, Baltimore RS, Shulman ST, Burns JC, Falace DA, Newburger JW, Pallasch TJ, Takahashi M, Taubert KA. Infective endocarditis: diagnosis, antimicrobial therapy, and management of complications: a statement for healthcare professionals from the Committee on Rheumatic Fever, Endocarditis, and Kawasaki Disease, Council on Cardiovascular Disease in the Young, and the Councils on Clinical Cardiology, Stroke, and Cardiovascular Surgery and Anesthesia, American Heart Association: endorsed by the Infectious Diseases Society of America. Circulation 111: e394-e434, 2005.

2. Haldar SM, O'Gara P. Infective Endocarditis. In: Fuster V, O'Rourke RA, Walsh RA, Poole-Wilson P (eds) Hurst's The Heart, McGraw Hill, p. 1975-2004, 2007.

3. Horstkotte D, Follath F, Gutschik E, Lengyel M, Oto A, Pavie A, Soler-Soler J, Thiene G, von GA, Priori SG, Garcia MA, Blanc JJ, Budaj A, Cowie M, Dean V,
Deckers J, Fernandez BE, Lekakis J, Lindahl B, Mazzotta G, Morais J, Oto A, Smiseth OA, Lekakis J, Vahanian A, Delahaye F, Parkhomenko A, Filipatos G, Aldershvile J, Vardas P. Guidelines on prevention, diagnosis and treatment of infective endocarditis executive summary; the task force on infective endocarditis of the European society of cardiology. European Heart Journal 25: 267-276, 2004 .

4. Sexton DJ. Vascular access infections in patients undergoing dialysis with special emphasis on the role and treatment of Staphylococcus aureus. Infectious Disease Clinics North American 15: 731-742, vii, 2001.

5. Tischler MD, Vaitkus PT. The ability of vegetation size on echocardiography to predict clinical complications: a meta-analysis. Journal American Society Echocardiography 10: 562-568, 1997.

6. Umana E, Ahmed W, Alpert MA. Valvular and perivalvular abnormalities in end-stage renal disease. The American Journal of Medical Sciences 325: 237-242, 2003.

7. Vuille C, Nidorf M, Weyman AE, Picard MH. Natural history of vegetations during successful medical treatment of endocarditis. American Heart Journal 128: 1200-1209, 1994. 